\title{
Lumbar Juxtafacet Cysts
}

\author{
Aykan ULUS ${ }^{1}$, Adnan ALTUN²$^{2}$, Alparslan SENEL ${ }^{1}$ \\ ${ }^{1}$ Ondokuz Mayıs University, Faculty of Medicine, Neurosurgery Department, Samsun, Turkey \\ ${ }^{2}$ Medicana International Samsun Hospital, Neurosurgery Clinic, Samsun, Turkey
}

Corresponding author: Aykan ULUS aykanulus@gmail.com

\section{ABSTRACT}

AIM: To evaluate the factors affecting the clinical and radiological findings of juxtafacet cyst patients.

MATERIAL and METHODS: Between January 2011 and December 2018, eight patients diagnosed with juxtafacet cyst were reviewed, retrospectively. Patient demographics; signs and symptoms; and neurological examination, radiological, and surgical findings were noted.

RESULTS: The mean age was 54 years (range, 34-69 years) with five (62.5\%) females and three (37.5\%) males. There were nine juxtafacet cysts in eight patients. Five cysts (55.5\%) were located at the L3-L4 level, two cysts (22.2\%) at the L4-L5 level, and two cysts $(22.2 \%)$ at the L5-S1 level. In all patients with L3-L4 cysts, the intercrest line was intersecting the spinal column at L4 vertebral body level. The most frequent symptoms were back pain and radiculopathy. Magnetic resonance imaging and computerized tomography revealed degenerative facet arthropathy in six patients $(75 \%)$. Three patients $(37.5 \%)$ had a medical history of trauma. One patient (12.5\%) was treated conservatively. Seven patients $(87.5 \%)$ were advised to undergo surgical treatment.

CONCLUSION: Degeneration and instability are the main causes of juxtafacet cysts. They are mainly seen at the L4-L5 level due to higher movement capacity of this level. But, if the intercrest line intersects the spinal column at higher levels, degeneration and instability risks move to upper levels, and juxtafacet cysts may occur at the L3-L4 or upper levels.

KEYWORDS: Synovial cyst, Ganglion cyst, Spine, Lumbar vertebrae

\section{INTRODUCTION}

S ynovial cysts are first described by Baker $(2,3)$ as cysts located in the leg, and by Vosshulte and Borger, (36) and Kao et al. $(16,17)$ as cysts located in the spine. The terms synovial and ganglion cysts are used interchangeably. The only difference is the synovial lining of synovial cysts. Juxtafacet cysts include both synovial and ganglion cysts $(6,12,16)$. Juxtafacet cysts are rare lesions; their incidence rates changes between $0.6 \%$ and $5.8 \%(9,24)$. They are usually seen in 6th decade and are mostly found in women $(6,14,15,21,28)$. Although they can be seen anywhere in the spinal column, juxtafacet cysts are mostly located in the lumbar region, particularly at the L4-L5 level $(4,6,14,15,19,35)$. They are located adjacent to the facet joints, posterolateral to the thecal sac. They may be unilateral or bilateral. Degenerative process due to physical stress is thought to play an important role in their pathogenesis $(14,38)$. Most of the patients with this condition have facet arthropathy or spondylolisthesis $(4,15,21,28,35)$. The juxtafacet cysts cause central or lateral recess stenosis. The most frequent complaints are back pain, radiculopathy, neurological deficits, neurogenic claudication, cauda equina syndrome $(6,8,14,15,19,21,29,38)$. The first imaging modality choice to diagnose this condition is magnetic resonance imaging (MRI) $(25,31)$. Computerized tomography (CT) and X-ray may be helpful in evaluating problems related to the bones, particularly spondylolisthesis and fusion need. Conservative treatment options usually have short-term benefits $(23,29)$. The most preferred way of treatment in the literature is surgery $(6,14,19,21,29,30)$. Surgery for this condition is performed to decompress stenosis, resect cyst, and maintain stability.

\section{MATERIAL and METHODS}

After the study protocol was approved by the institutional re- 
view board (Date: 28.06.2019, B.30.2.ODM.0.20.08/554), eight patients with a diagnosis of juxtafacet cyst between January 2011 and December 2018 were reviewed retrospectively. The patients' records were reviewed for demographic and clinical information including age; gender; signs and symptoms; and neurological examination, radiological, and surgical findings.

The data used in this study are obtained from previously recorded files retrospectively, and patient anonymity is maintained in the manuscript.

\section{RESULTS}

The mean age of the participants was 54 years (range, 34-69 years); five females $(62.5 \%)$ and three males $(37.5 \%)$ were included in this study. There were nine juxtafacet cysts in eight patients. One patient has two cysts at the same level. Five cysts $(55.5 \%)$ are located at the L3-L4 level, two cysts $(22.2 \%)$ at the L4-L5 level, and two cysts (22.2) at L5-S1 level (Table I).

Table I: Characteristics, Symptoms and Findings, Possible Etiological Factors, Radiological Findings, and Treatment of the Patients

\begin{tabular}{|c|c|c|c|c|c|c|c|c|c|}
\hline Case & $\begin{array}{l}\text { Age/ } \\
\text { Gender }\end{array}$ & $\begin{array}{c}\text { Back } \\
\text { pain }\end{array}$ & Radiculopathy & $\begin{array}{l}\text { Motor } \\
\text { deficit }\end{array}$ & $\begin{array}{c}\text { Sensorial } \\
\text { defisit }\end{array}$ & Level & Aetiology & Radiology & Treatment \\
\hline 1 & $\begin{array}{c}66 / \\
\text { Female }\end{array}$ & - & + & - & + & L3-L4 & $\begin{array}{c}\text { Degenerative } \\
\text { and Chronic } \\
\text { trauma }\end{array}$ & $\begin{array}{l}\text { L4-5 listhesis, } \\
\text { L3-L4 right } \\
\text { synovial cyst L5 } \\
\text { old compression }\end{array}$ & $\begin{array}{c}\text { Right L3-L4 } \\
\text { decompression and } \\
\text { cystectomy, L4-L5 } \\
\text { decompression, L4-5 } \\
\text { instrumentation, right } \\
\text { L3 ganglioneuroma } \\
\text { (incidental) }\end{array}$ \\
\hline 2 & $\begin{array}{l}61 / \\
\text { Male }\end{array}$ & + & + & + & + & L3-L4 & Acute trauma & $\begin{array}{l}\text { L3-L4 listhesis, } \\
\text { L3-L4 right huge } \\
\text { synovial cyst }\end{array}$ & $\begin{array}{l}\text { Right L3-L4 } \\
\text { decompression and } \\
\text { cystectomy, L3-L4 } \\
\text { instrumentation }\end{array}$ \\
\hline 3 & $\begin{array}{l}47 / \\
\text { Male }\end{array}$ & + & + (Bilateral) & - & - & L4-L5 & Degenerative & $\begin{array}{c}\mathrm{L} 4-\mathrm{L} 5 \text { left } \\
\text { protruded disc } \\
\text { and synovial cyst }\end{array}$ & $\begin{array}{l}\text { Left L4-L5 } \\
\text { decompression } \\
\text { and cystectomy, } \\
\text { L4-L5 discectomy } \\
\text { (proposed) }\end{array}$ \\
\hline 4 & $\begin{array}{c}57 / \\
\text { Female }\end{array}$ & + & - & - & - & L3-L4 & Degenerative & $\begin{array}{l}\text { L3-L4 left } \\
\text { synovial cyst }\end{array}$ & Conservative \\
\hline 5 & $\begin{array}{c}\text { 69/ } \\
\text { Female }\end{array}$ & + & + & + & + & L5-S1 & $\begin{array}{l}\text { Degenerative, } \\
\text { She was } \\
\text { operated } \\
\text { for lumbar } \\
\text { degenerative } \\
\text { disease } 2 \\
\text { months ago }\end{array}$ & $\begin{array}{l}\text { L4-L5 listhesis, } \\
\text { L2-L5 } \\
\text { instrumented, L5- } \\
\text { S1 right synovial } \\
\text { cyst }\end{array}$ & $\begin{array}{c}\text { Right L5-S1 } \\
\text { decompression and } \\
\text { cystectomy }\end{array}$ \\
\hline 6 & $\begin{array}{c}50 / \\
\text { Female }\end{array}$ & + & + (Bilateral) & - & - & $\begin{array}{l}\text { L3-L4 } \\
\text { (Bilateral) }\end{array}$ & Degenerative & $\begin{array}{l}\text { July } 2017 \text { MRI: } \\
\text { Bilateral L3-L4 } \\
\text { synovial cyst } \\
\text { January 2018 } \\
\text { MRI: Left L3-L4 } \\
\text { cyst }\end{array}$ & $\begin{array}{c}\text { Bilateral L3-L4 } \\
\text { decompression and } \\
\text { bilateral cystectomy, } \\
\text { Left L4-L5 } \\
\text { discectomy }\end{array}$ \\
\hline 7 & $\begin{array}{c}48 / \\
\text { Female }\end{array}$ & + & + & - & - & L5-S1 & Degenerative & $\begin{array}{l}\text { L5-S1 left } \\
\text { synovial cyst }\end{array}$ & $\begin{array}{l}\text { Left L5-S1 } \\
\text { decompression and } \\
\text { cystectomy }\end{array}$ \\
\hline 8 & 34/Male & - & - & - & + & L4-L5 & $\begin{array}{l}\text { Chronic } \\
\text { Trauma }\end{array}$ & $\begin{array}{c}\text { L4-L5 left } \\
\text { synovial cyst L3- } \\
\text { L4 and L4-L5 disc } \\
\text { degeneration, } \\
\text { lumbarisation }\end{array}$ & $\begin{array}{l}\text { Did not accept } \\
\text { surgery }\end{array}$ \\
\hline
\end{tabular}

L: Lumbar, S: Sacral, MRI: Magnetic resonance imaging. 
The most frequent symptoms were back pain and radiculopathy. Six patients $(75 \%)$ suffer from back pain, and six patients $(75 \%)$ suffer from radiculopathy. While four patients $(50 \%)$ have sensorial deficits, two patients $(25 \%)$ have motor deficits. Although there was only one bilateral cyst (12.5\%), two patients (25\%) had bilateral complaints.

$\mathrm{MRI}$ and $\mathrm{CT}$ revealed degenerative facet arthropathy in six (75\%) patients. Three patients $(37.5 \%)$ had a medical history of trauma; two chronic and one acute trauma. One of them has old L5 compression fracture.

Spondylolisthesis was noted in three (37.5\%) patients - at the same level with the cyst in one patient and at different level in another. Pedicle screw instrumentation (L2-L5) was performed on the third patient with spondylolisthesis in another hospital 2 months ago. No cyst was noted in MRI at that time. But a new $\mathrm{MRI}$ result, which was performed due to onset neurological deficit, revealed a juxtafacet cyst at the L5-S1 level, adjacent to the instruments (Figure 1A, B).
There were disc degenerations at the same level with the cysts in two patients $(25 \%)$ and lumbarization in one patient (12.5\%).

One patient (12.5\%), who suffered from back pain without neurological deficit, was treated conservatively. Seven patients were advised to undergo surgical treatment. One of them, who had sensorial deficit and chronic trauma history, refused to undergo surgery. The remaining six patients $(75 \%)$ underwent surgery. Standard surgical approach was partial hemilaminectomy, mesial facetectomy, foraminotomy, and cyst resection. Two patients $(25 \%)$ required instrumentation and fusion due to spondylolisthesis. All cysts are removed totally.

The patient who has two cysts had two MRI in 6 months. Bilateral L3-L4 juxtafacet cyst was noted on her first MRI, but the cyst on the right side disappeared on the last MRI (Figure 2A-C). Decompression was performed on both sides since she was suffering from bilateral leg pain. The right cyst that
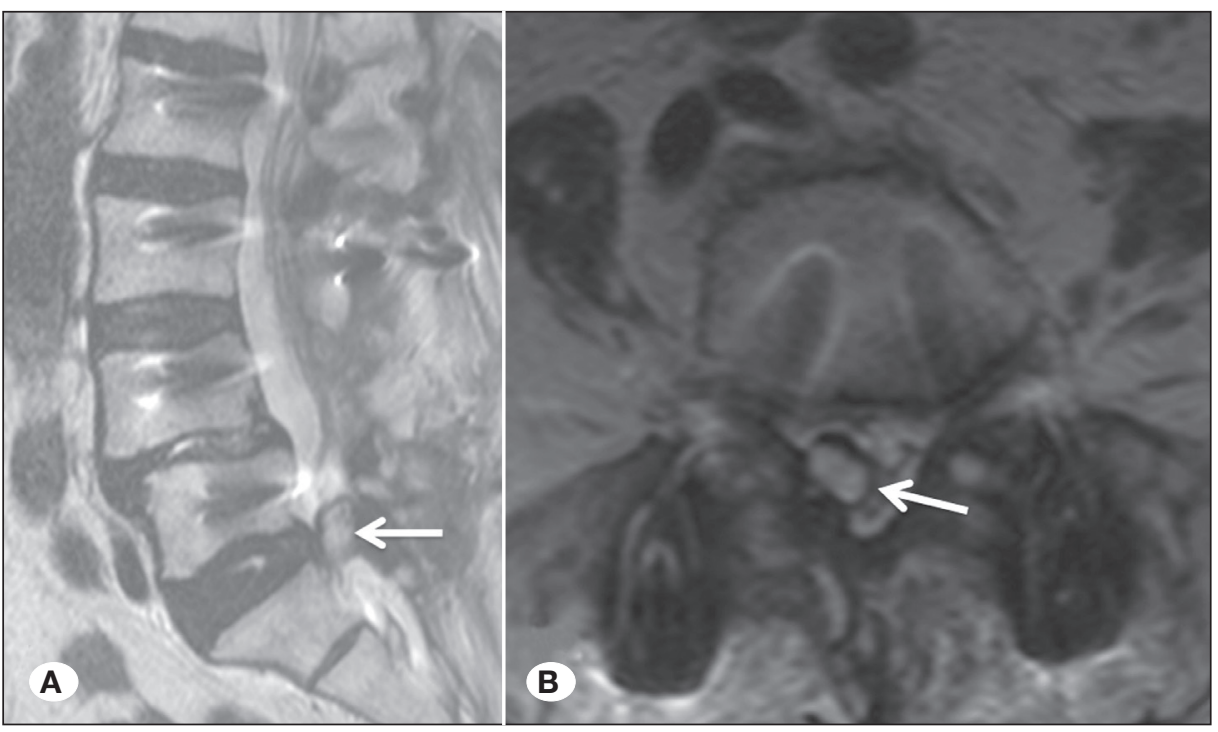

Figure 1: Juxtafacet cyst at the L5-S1 level, adjacent to the instruments. A) Sagittal T2W MRI (arrow shows juxtafacet cyst). B) Axial T2W MRI (arrow shows right juxtafacet cyst).
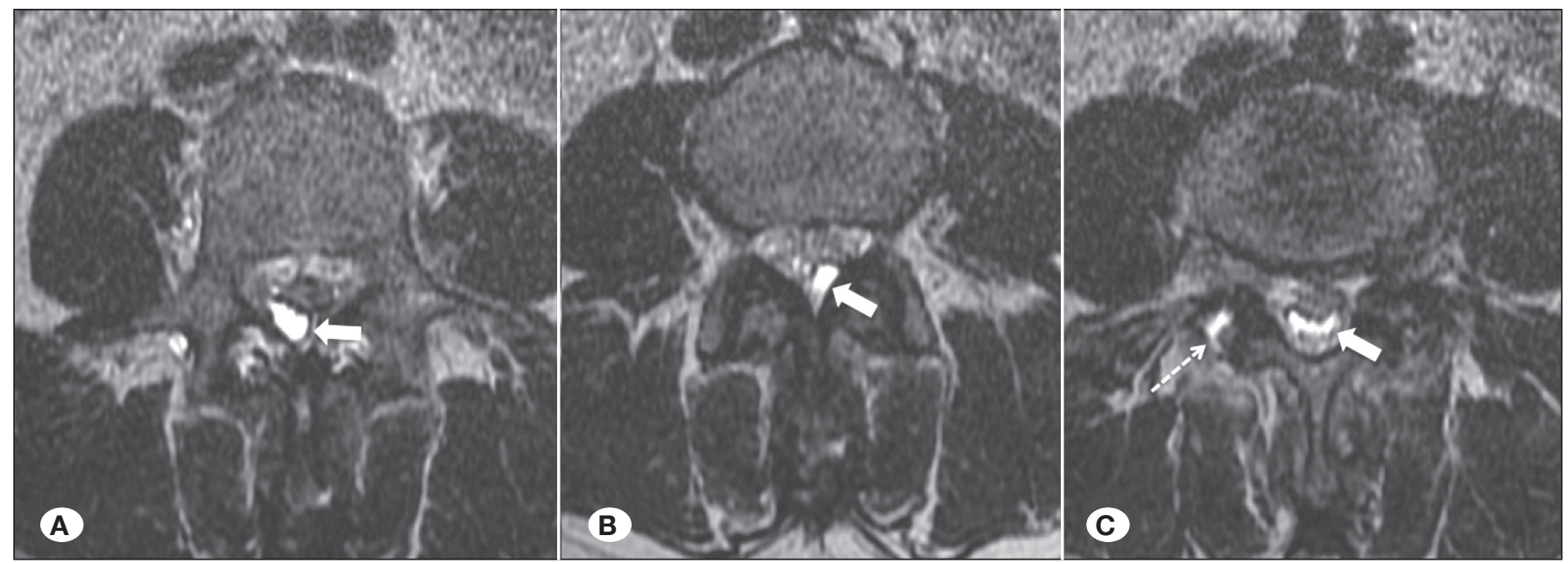

Figure 2: Bilateral juxtafacet cysts (bold arrows), A) right cyst, B) left cyst. Right cyst disappeared later, C) cyst and facet fluids are isointense (dashed arrow: facet fluid; bold arrow: cyst fluid). 
disappeared on the second MRI was then found, and both cysts are removed totally.

An incidental ganglioneuroma, which is not related to the cysts, was removed totally.

\section{DISCUSSION}

Synovial cysts are first described by Baker as cysts located in the leg, in $1877(2,3)$. They can be found anywhere in the body adjacent to the joints. The first spinal synovial cysts were reported by Vosshulte and Borger (36) in German literature, and by Kao et al. $(16,17)$ in English literature in 1950 and 1968, respectively. Spinal cysts are classified as true cysts and pseudocysts. Synovial cysts are true cysts, which have synovial lining and contain clear or xanthochromic fluid. They are located adjacent to the facet joint, and there may be a connection between cyst and facet joint $(6,12,38)$. Pseudocysts are divided into ganglion cysts and ligamentous cysts. They have no synovial lining. Ligamentous cysts are found in ligamentum flavum or posterior longitudinal ligament. Ganglion cysts are located in periarticular fibrous tissue adjacent to the facet joint, but they have no connection with the joint and have no synovial lining. There is no difference between synovial and ganglion cysts regarding clinical findings, diagnosis, treatment, or prognosis. It is only a pathological concern $(14,21,30)$. Some authors thought both entities are different steps of a pathological cycle; they also thought that a synovial cyst may turn into a ganglion cyst or vice versa $(15,32,38)$. Both synovial cysts and ganglion cysts are also called juxta-articular cyst or juxtafacet cyst.

$\mathrm{MRI}$ and CT are the best imaging modalities for the diagnosis of juxtafacet cysts. The synovial cysts in the entire body were thought as rare lesions before MRI and CT era, and even juxtafacet cysts are rarer. Only 26 cases of juxtafacet cysts had been reported till 1986 (20). In 2016, total juxtafacet cysts reported in English literature reached to 3041 (6). Their incidence was reported between $0.6 \%$ and $5.8 \%$ in patients investigated by CT or MRI, due to various complaints $(9,24)$. The increase on the incidence is explained with the advances on imaging modalities.

The juxtafacet cysts are usually seen in the $6^{\text {th }}$ decade, ranging between 14 and 86 years. The mean age of all reported patients until 2016 is 62.6 years (6). The mean age of our patients (54 years, range between 34 and 69 years) is low compared with that in the literature.

Most of the publications report higher rates of juxtafacet cyst in females, but there are also a few publications reporting higher rates in males or equal in both genders $(15,21,26)$. Female rate in the literature is $56 \%$ (6). In this study $62.5 \%$ of the patients were female, which is slightly higher than that in the literature.

Degeneration and trauma are thought to be the main causes of juxtafacet cyst formation. Physical stress or microtrauma facilitates degeneration; thus, excessive joint mobility causes herniation of the synovium $(14,38)$. Degenerative facet arthropathy is frequently seen in patients with juxtafacet cysts. Banning et al. and Hsu et al. reported high rates of facet arthropathy in their studies, which are $90 \%$ and $75 \%$, respectively $(4,15)$. Spondylolisthesis is another frequent problem that supports the degeneration theory. Although the mean rate of spondylolisthesis is $31 \%$ in the literature, it was reported to be up to $82 \%$ in some publications $(6,19)$. In our study, facet arthropathy and spondylolisthesis rates are $75 \%$ and $37.5 \%$, respectively, concordant with the literature.

Trauma also may cause juxtafacet cysts, but it is not as frequent as degeneration $(11,34)$. In the literature, only $7 \%$ of the patients mentioned trauma in their medical history (6). Degeneration is the most important and frequent factor for cyst formation both in elder and young patient populations, but the rate of traumatic etiology is higher in younger patients (6). In our study, the rate of patients who had trauma in their history was $37.5 \%$. Our patients are younger and trauma rates are higher, as compared with the literature. These both findings support traumatic theory in younger patients.

Juxtafacet cysts can be seen in any level in the spinal column, even in the C1-C2 level. But 92\% of them are found in the lumbar spine. Cervical and thoracic spines are less frequently involved, with a rate of $6.3 \%$ and $1.6 \%$, respectively. Bruder commented that because the thoracic spine is the most rigid part, only a few cases of juxtafacet cysts in this region have been reported, emphasizing the significance of movement and physical stress in the development of the cysts (6). Juxtafacet cysts are most frequently located at the L4-L5 level $(4,6,14,15,19,35)$. Of all cases, $58.4 \%$ is located at the L4-L5 level, $14.2 \%$ at the L5-S1 level, and $14.1 \%$ at the L3-L4 level (6). This predilection has been attributed to high incidence of degenerative spondylosis and spinal instability at the L4-L5 level. In our study, somewhat, the most frequently involved level was the L3-L4 level (55.5\%), following by L4-L5 and L5-S1 levels with two cases (22.2\%) each. It is important to note that in all of our patients with L3-L4 cysts, the intercrest line was intersecting the spinal column at L4 vertebral body level. Intercrest line is used to explain some features of adult degenerative scoliosis. According to this concept, if the intercrest line intersects the spinal column from or above the L4 vertebral body (deep-seated L5), the risk of degenerative scoliosis progression decreases due to more stable lower lumbar balance $(10,13,22,37)$. Similarly, high intercrest line (deep-seated L5) may have an important role in juxtafacet cyst patients, by stabilizing lower levels, and transporting the risk of degeneration and instability to higher levels. Although it cannot be statistically proven due to the low number of patients in this study, we assumed that the higher level of intercrest line of patients with cysts at the L3-L4 level than the other levels may be responsible for the increased L3-L4 level involvement in our study. These opinions or thoughts need to be investigated in greater series by comparing different levels, with regard to intercrest line.

One of our patients, previously instrumented between $\mathrm{L} 2$ and L5 due to spondylolisthesis, had a cyst at the L5-S1 level, adjacent to the instrument (Figure 1A, B). We thought that physical stress at the adjacent level due to the instrument played an important role for the development of the cyst. 
Juxtafacet cysts are located posterolateral to the thecal sac. They cause central or lateral spinal stenosis and manifest as radiculopathy, back pain, sensorial deficit, motor deficit, neurogenic claudication, and cauda equine syndrome $(6,8,14,15,19,21,27,29,38)$. Our results were similar to that in the literature. The most frequent complaints were back pain and radiculopathy following sensorial and motor deficits.

One of our patients had two cysts as we mentioned in our results. She had bilateral L3-L4 cysts in her first MRI. But due to changing complaints, she had a new MRI was performed 6 months later. This time, the cyst on her right side disappeared but was later found. Both cysts were removed through surgery. There are publications about cysts that disappear in repeating MRI depending on the position. Niggeman et al. suggested that if the bright signal of the cyst is isointense with the joint fluid on MRI, it may show the connection between the cyst and the joint (24). This connection may allow fluid transport between the cyst and the joint; thus, positional disappearance of the cyst occurs. Similarly, in our patient, the cyst and the joint fluids were isointense with each other, suggesting a connection between them (Figure 2A-C). Probably, the surgical position provoked the fluid transport through the cyst, so the cyst was found and removed.

The main treatment options for juxtafacet cysts are conservative and surgical modalities. The conservative treatment options are bed rest, brace, needle aspiration, and steroid injection to the joint. Although some publications advocated the long-term effects of conservative treatment $(1,5)$, most of the authors reported that its benefits do not last long $(23,29,32,33)$. Most of the publications in the literature are about surgical treatment, with regard to juxtafacet cysts $(4,6,14,15,18,21,29-31,35)$. Khan and Girardi preferred surgical treatment, after performing all conservative treatment modalities for 6 months (18). All of our patients without neurological deficit received conservative treatment initially. Surgery is carried out in case of neurological deficit or failure of conservative treatment. The surgery aims to decompress the spinal canal and resect the cyst. We preferred partial hemilaminectomy for decompression by tailoring it for each patient individually. Previous publications advocated more extensive decompression such as hemilaminectomy of the cyst level and partial hemilaminectomy of upper and lower levels $(7,8,38)$. But, in recent publications, authors preferred only partial hemilaminectomy of the cyst level (6). This progress may be attributed to the use of operating microscope in spine surgery.

Surgery outcome, which was reported in the literature, is effective especially for back and leg pain and sensorial deficits; success rates are approximately $85 \%$ for each. When it comes to motor deficits, the full recovery rate is about $14 \%$ (6).

\section{CONCLUSION}

The juxtafacet cysts are space-occupying lesions within the spinal canal, adjacent to facet joints. They cause central or lateral canal stenosis. Degeneration and instability are the main factors for the cyst formation. Trauma is a less frequent cause, and this type of cyst is mostly seen in younger patients. As most of the movement of the lumbar spine occurs at the L4-L5 level, degeneration, instability, and the juxtafacet cysts are usually seen at this level. If the intercrest line intersects the spinal column at higher levels, degeneration and instability risk moves to upper levels, and the juxtafacet cysts may occur at the L3-L4 or upper levels. But this opinion needs to be investigated in greater patient population.

\section{ACKNOWLEDGEMENTS}

Preparation for publication of this article is partly supported by Turkish Neurosurgical Society.

\section{REFERENCES}

1. Abrahams JJ, Wood GW, Eames FA, Hicks RW: CT-guided needle aspiration biopsy of an intraspinal synovial cyst (ganglion): Case report and review of the literature. AJNR Am J Neuroradiol 9:398-400, 1988

2. Baker WM: On the formation of synovial cysts in the leg in connection with disease of the knee-joint. St. Bartholomew's Hospital Reports XIII:245-261, 1877

3. Baker WM: On the formation of synovial cysts in the leg in connection with disease of the knee-joint, 1877. Clin Orthop Relat Res 299:2-10, 1994

4. Banning CS, Thorell WE, Leibrock LG: Patient outcome after resection of lumbar juxtafacet cysts. Spine (Phila $\mathrm{Pa}$ 1976) 26:969-972, 2001

5. Bjorkengren AG, Kurz LT, Resnick D, Sartoris DJ, Garfin SR: Symptomatic intraspinal synovial cysts: Opacification and treatment by percutaneous injection. AJR Am J Roentgenol 149:105-107, 1987

6. Bruder M, Cattani A, Gessler F, Droste C, Setzer M, Seifert V, Marquardt G: Synovial cysts of the spine: long-term follow-up after surgical treatment of 141 cases in a single-center series and comprehensive literature review of 2900 degenerative spinal cysts. J Neurosurg Spine 27:256-267, 2017

7. Epstein NE: Lumbar laminectomy for the resection of synovial cysts and coexisting lumbar spinal stenosis or degenerative spondylolisthesis: An outcome study. Spine (Phila Pa 1976) 29:1049-1055; discussion 1056, 2004

8. Epstein NE: Lumbar synovial cysts: A review of diagnosis, surgical management, and outcome assessment. J Spinal Disord Tech 17:321-325, 2004

9. Eyster EF, Scott WR: Lumbar synovial cysts: Report of eleven cases. Neurosurgery 24:112-115, 1989

10. Faraj SS, Holewijn RM, van Hooff ML, de Kleuver M, Pellise F, Haanstra TM: De novo degenerative lumbar scoliosis: A systematic review of prognostic factors for curve progression. Eur Spine J 25:2347-2358, 2016

11. Franck Jl, King RB, Petro GR, Kanzer MD: A posttraumatic lumbar spinal synovial cyst: Case report. J Neurosurg 66:293296, 1987

12. Ganau M, Ennas F, Bellisano G, Ganau L, Ambu R, Faa G, Maleci A: Synovial cysts of the lumbar spine-pathological considerations and surgical strategy. Neurol Med Chir (Tokyo) 53:95-102, 2013 
13. Hong JY, Suh SW, Modi HN, Hur CY, Song HR, Park JH: The prevalence and radiological findings in 1347 elderly patients with scoliosis. J Bone Joint Surg Br 92:980-983, 2010

14. Howington JU, Connolly ES, Voorhies RM: Intraspinal synovial cysts: 10-year experience at the Ochsner Clinic. J Neurosurg 91:193-199, 1999

15. Hsu KY, Zucherman JF, Shea WJ, Jeffrey RA: Lumbar intraspinal synovial and ganglion cysts (facet cysts). Ten-year experience in evaluation and treatment. Spine (Phila Pa 1976) 20:80-89, 1995

16. Kao CC, Uihlein A, Bickel WH, Soule EH: Lumbar intraspinal extradural ganglion cyst. J Neurosurg 29:168-172, 1968

17. Kao CC, Winkler SS, Turner JH: Synovial cyst of spinal facet: Case report. J Neurosurg 41:372-376, 1974

18. Khan AM, Girardi F: Spinal lumbar synovial cysts. Diagnosis and management challenge. Eur Spine J 15:1176-1182, 2006

19. Khan AM, Synnot K, Cammisa FP, Girardi FP: Lumbar synovial cysts of the spine: An evaluation of surgical outcome. J Spinal Disord Tech 18:127-131, 2005

20. Kjerulf TD, Terry DW Jr, Boubelik RJ: Lumbar synovial or ganglion cysts. Neurosurgery 19:415-420, 1986

21. Lyons MK, Atkinson JL, Wharen RE, Deen HG, Zimmerman RS, Lemens SM: Surgical evaluation and management of lumbar synovial cysts: The Mayo Clinic experience. J Neurosurg 93:53-57, 2000

22. MacGibbon B, Farfan HF: A radiologic survey of various configurations of the lumbar spine. Spine (Phila Pa 1976) 4:258-266, 1979

23. Metellus P, Fuentes S, Adetchessi T, Levrier O, FloresParra I, Talianu D, Dufour H, Bouvier C, Manera L, Grisoli F: Retrospective study of 77 patients harbouring lumbar synovial cysts: Functional and neurological outcome. Acta Neurochir (Wien) 148:47-54; discussion 54, 2006

24. Niggemann P, Kuchta J, Hoeffer J, Grosskurth D, Beyer HK, Delank KS: Juxtafacet cysts of the lumbar spine: A positional MRI study. Skeletal Radiol 41:313-320, 2012

25. Nijensohn E, Russell EJ, Milan M, Brown T: Calcified synovial cyst of the cervical spine: CT and MR evaluation. J Comput Assist Tomogr 14:473-476, 1990

26. Onofrio BM, Mih AD: Synovial cysts of the spine. Neurosurgery 22:642-647, 1988
27. Park HS, Sim HB, Kwon SC, Park JB: Hemorrhagic lumbar synovial cyst. J Korean Neurosurg Soc 52:567-569, 2012

28. Parlier-Cuau C, Wybier M, Nizard R, Champsaur P, Le Hir P, Laredo JD: Symptomatic lumbar facet joint synovial cysts: Clinical assessment of facet joint steroid injection after 1 and 6 months and long-term follow-up in 30 patients. Radiology 210:509-513, 1999

29. Pirotte B, Gabrovsky N, Massager N, Levivier M, David P, Brotchi J: Synovial cysts of the lumbar spine: Surgery-related results and outcome. J Neurosurg 99:14-19, 2003

30. Sabo RA, Tracy PT, Weinger JM: A series of 60 juxtafacet cysts: Clinical presentation, the role of spinal instability, and treatment. J Neurosurg 85:560-565, 1996

31. Salmon B, Martin D, Lenelle J, Stevenaert A: Juxtafacet cyst of the lumbar spine. Clinical, radiological and therapeutic aspects in 28 cases. Acta Neurochir (Wien) 143:129-134, 2001

32. Shah RV, Lutz GE: Lumbar intraspinal synovial cysts: Conservative management and review of the world's literature. Spine J 3:479-488, 2003

33. Slipman CW, Lipetz JS, Herzog RJ, Vresilovic EJ: Nonsurgical treatment for radicular of pain of zygoapophyseal joint cyst origin: Therapeutic selective nerve root block. Arch Phys Med Rehabil 81:1119-1122, 2000

34. Sypert GW, Leech RW, Harris AB: Posttraumatic lumbar epidural true synovial cyst. Case report. J Neurosurg 39:246248, 1973

35. Trummer M, Flaschka G, Tillich M, Homann CN, Unger F, Eustacchio S: Diagnosis and surgical management of intraspinal synovial cysts: Report of 19 cases. J Neurol Neurosurg Psychiatry 70:74-77, 2001

36. Vosschulte K, Borger G: Anatomische and funktinonelle untersuchugen iiber ben bandsheibenprolaps. Langenbecks Arch Klin Chir 265:329-355, 1950

37. Weinstein SL, Ponseti IV: Curve progression in idiopathic scoliosis. J Bone Joint Surg Am 65:447-455, 1983

38. Yarde WL, Arnold PM, Kepes JJ, O’Boynick PL, Wilkinson SB, Batnitzky S: Synovial cysts of the lumbar spine: Diagnosis, surgical management, and pathogenesis. Report of eight cases. Surg Neurol 43:459-464; discussion 465, 1995 